\title{
Separation of cobalt, neodymium and dysprosium using amorphous zirconium phosphate
}

\author{
Xu, Junhua
}

2018-01

Xu , J , Koivula , R T, Zhang , W , Wiikinkoski , E W , Hietala , S \& Harjula , R O 2018 , ' Separation of cobalt, neodymium and dysprosium using amorphous zirconium phosphate ' , Hydrometallurgy, vol. 175 , pp. 170-178 . https://doi.org/10.1016/j.hydromet.2017.11.010

http://hdl.handle.net/10138/321807

https://doi.org/10.1016/j.hydromet.2017.11.010

cc_by_nc_nd

acceptedVersion

Downloaded from Helda, University of Helsinki institutional repository.

This is an electronic reprint of the original article.

This reprint may differ from the original in pagination and typographic detail.

Please cite the original version. 


\title{
Separation of Cobalt, Neodymium and Dysprosium Using Amorphous Zirconium Phosphate
}

\author{
Junhua $\mathrm{Xu}^{\mathrm{a}, *}$, Risto Koivula ${ }^{\mathrm{a}}$, Wenzhong Zhang ${ }^{\mathrm{a}}$, Elmo Wiikinkoski ${ }^{\mathrm{a}}$, Sami Hietala ${ }^{\mathrm{b}}$, Risto Harjula $\dagger^{\mathrm{a}}$ \\ ${ }^{\text {a }}$ Department of Chemistry—Radiochemistry, FI-00014 University of Helsinki, Finland \\ ${ }^{\mathrm{b}}$ Department of Chemistry, FI-00014 University of Helsinki, Finland
}

$†$ Deceased, September 11, 2017.

(Corresponding author's email: junhua.xu@helsinki.fi)

\section{Abstract}

The purpose of this study was to investigate the separation of Co, Nd and Dy from a ternary Co-Nd-Dy solution using amorphous zirconium phosphate (am-ZrP). Am-ZrP was synthesized by a precipitation method at room temperature and subsequently characterized by Fourier transform-infrared spectrometry, thermogravimetry, scanning electron microscopy, X-ray diffraction, solid-state ${ }^{31} \mathrm{P}$ magic angle spinning nuclear magnetic resonance spectrometry and sodium hydroxide titration (with and without background salt). The ion exchange kinetics of am-ZrP that were determined in ternary $1 \mathrm{mM}$ equimolar solutions at equilibrium $\mathrm{pH}$ 2.5. The effect of $\mathrm{pH}$ on the adsorption was studied in ternary $1 \mathrm{mM}$ equimolar solutions and the uptakes of the metals increased with increasing $\mathrm{pH}$ until approximately $\mathrm{pH}$ 3.5. The adsorption isotherms of $\mathrm{Co}, \mathrm{Nd}$ and $\mathrm{Dy}$ were tested in a series of ternary equimolar solution, the total uptake amounted to $4.13 \mathrm{meq} / \mathrm{g}$ at $\mathrm{pH} \sim 3.0$. The preference of am-ZrP for these metals occurred in decreasing order Dy $>\mathrm{Nd}>>$ Co. The separation of Co, Nd and Dy from their $1 \mathrm{mM}$ equimolar ternary mixture was investigated on an am-ZrP column. Effects of loading $(7.8 \%, 62 \%$ and $100 \%)$ on the separation were compared by measuring the corresponding HNO3 elution fractions. It was found that with a lower metal loading of $7.8 \%$, three clear elution bands were obtained. Am-ZrP exhibited selective separation properties towards the ternary Co-Nd-Dy system, which contribute to the future scale-up studies for the recycling of $\mathrm{NdFeB}$ magnets.

\section{Keywords}

Zirconium phosphate, NdFeB magnet, Ion exchange, Column separation, Rare earth separation 


\section{Introduction}

Neodymium-iron-boron $(\mathrm{NdFeB})$ permanent magnets have been widely used in computer hard-disk drives, hybrid and electric vehicles, wind turbines, household electrical appliances and small electronic devices (Binnemans et al., 2013). Quantities of end-of-life (EOL) NdFeB permanent magnets have been accumulating year by year, due to their long lifecycles that range up to 30 years. EOL NdFeB magnets contain about 31-32\% rare-earth elements (REEs) such as Nd, Pr, Dy, Tb and Gd (Yang et al., 2008). In addition, Co is added to NdFeB magnets with a comparable content of Dy (El-Moneim et al., 2002). The purpose of adding Co is to improve corrosion resistance of NdFeB magnets (El-Moneim et al., 2002). Recycling of REEs from EOL NdFeBs has become a significant activity in the NdFeB market and will play an important role in the future supply of REEs in the magnet sector (Rademaker et al., 2013).

Recently, many researches using physical or chemical way to recycle REEs from EOL NdFeB magnets took place. The processes for REEs separation from computer hard disk drives have been well developed to produce demagnetized hydride alloy powder in atmospheric pressure hydrogen (Sheridan et al., 2014; Walton et al., 2015). In order to obtain the individual REEs, the NdFeB alloy powder is usually first leached by mineral acids into aqueous solution. However, the high concentration of Fe ion in acid leaching solution is the big problem for the further REEs separation. Hence, an ionic liquid with homomorphic behaviour was used for a roasted magnet for Fe ion removal to achieve an efficient separation. Those authors extracted Fe into the ionic liquid phase, whereas Nd, Dy and Co remained in the aqueous phase. (Dupont \& Binnemans, 2015).

For commercial REEs production, they are firstly extracted from ores using mineral acids leaching. The obtained pregnant leaching solution is then treated by solvent extraction (SX) for the separation of REEs. During the SX operation, REEs are transferred to an organic phase using REE-selective extractants. Apart from the demerit of using volatile organic solvent as a diluent, the separation efficiency of individual REE is not satisfying. Due to the similarity of the REEs, often hundreds of separation stages (utilising mixer-settler units) and complicated flowsheets with reflux are needed in the actual industrial scale separation to obtain individual REE. In fact, the REEs are still present in the strip liquor/raffinate after many stages even though the extraction rate is higher than 99\% (Brown et al., 1979; Morais et al., 2004; Nakamura et al., 2007). In this case, the separation process of ion exchange could be a viable supplement to the continuous REEs recycling after solvent extraction in industry.

Ion exchange technology is commonly used to purify solutions by removing the dissolved ions by electrostatic adsorption onto the internal and external surfaces of ion exchange materials of various physical forms. Before the 1960s, the separation process of ion exchange was the dominated method to obtain the individual REE. Nowadays, ion 
exchange method is still used industrially to prepare high purity REEs even though solvent extraction plays the key role on the large scale REEs production (Inamuddin \& Luqman, 2012; Xie et al., 2014).

Inorganic ion exchangers are generally much more selective than organic resins for metal ions. Typically such high selectivities arise from their porous and ordered, rigid structures that exhibit ion sieve functionality (Yang, 2011). Inorganic ion exchangers have been used on a large scale mainly for water purification and removal of radionuclides from nuclear waste effluents (Lehto \& Harjula, 1999). Zirconium phosphates (ZrPs) have received wide attention because of their excellent properties, such as high Brønsted acidity, very high thermal and chemical stability, insolubility in acids and resistance to ionizing radiation. The use of $\mathrm{ZrPs}$ has been promising for the following areas: catalysts (Emig \& Hofmann, 1983; Rao et al., 2006), cation ion exchangers (Clearfield, 1984), matrices (Bestaoui et al., 2006) and solid electrolytes (Cook \& Sammells, 1991). However, crystalline ZrP granules tend to form submicron particles and are thus difficult to be used in a fixed-bed column (Xu et al., 2017). It is worthy to mention that amorphous $\mathrm{ZrP}(\mathrm{am}-\mathrm{ZrP})$ has a relatively larger specific surface area and a sufficient content of microspores, which can enhance its function as ion exchangers, catalysts and adsorbents (Sydorchuk et al., 2011). Amorphous ZrP (Am-ZrP) has been thoroughly studied in thermodynamics of alkali metal ion exchange (Kullberg \& Clearfield, 1981), heavy metals removal (Zhang et al., 2008), radioisotope adsorption (Dyer et al., 1997). Nevertheless, little is known about their adsorption and separation behavior on cobalt and the REEs.

Herein, am-ZrP was investigated in our present study for its potential in the separation and recovery of Co, $\mathrm{Nd}$ and Dy from a Co-Nd-Dy ternary solution system. The synthesis and characterizations of the am-ZrP material in addition to the identification of its acidity, selectivity, and isothermal adsorption for $\mathrm{Co}$, $\mathrm{Nd}$ and $\mathrm{Dy}$ ions. The kinetic mechanism of am-ZrP material and preliminary batch elution using mineral acids were also investigated. Our aim was to avoid the use of organic complexing agents by using simple mineral acids to separate $\mathrm{Nd}$ and Dy from each other and Co by relying on the separation capability of the $\mathrm{ZrP}$ material itself. Finally, column loading and eluting using only $\mathrm{HNO}_{3}$ was tested.

\section{Experimental}

\subsection{Chemicals}

Zirconium tetrachloride $\left(\mathrm{ZrCl}_{4},>99.5 \%\right)$, hydrochloric acid $(\mathrm{HCl},>37 \%)$, phosphoric acid $\left(\mathrm{H}_{3} \mathrm{PO}_{4}, 85 \%\right)$ were used as precursors for the material synthesis. Cobalt nitrate hexahydrate $\left(\mathrm{Co}\left(\mathrm{NO}_{3}\right)_{2} \cdot 6 \mathrm{H}_{2} \mathrm{O}, 98 \%\right)$, neodymium nitrate hexahydrate $\left(\mathrm{Nd}\left(\mathrm{NO}_{3}\right)_{3} \cdot 6 \mathrm{H}_{2} \mathrm{O}, 99.9 \%\right)$, dysprosium nitrate hydrate $\left(\mathrm{Dy}\left(\mathrm{NO}_{3}\right)_{3} \cdot \mathrm{xH}_{2} \mathrm{O} 99.9 \%\right)$, sulfuric acid $\left(\mathrm{H}_{2} \mathrm{SO}_{4}\right.$, 95\% 97\%), nitric acid $\left(\mathrm{HNO}_{3}, 67 \%-69 \%\right)$, hydrochloric acid $(\mathrm{HCl},>37 \%)$, phosphoric acid $\left(\mathrm{H}_{3} \mathrm{PO}_{4}, 85 \%\right)$ were used in the ion exchange experiments. All chemicals were purchased from Sigma-Aldrich except for the $\mathrm{H}_{2} \mathrm{SO}_{4}$, which was 
purchased from J. T. Baker and used without further purification. Milli-Q water (Merck Millipore) with the resistivity of $18.2 \mathrm{M} \Omega \mathrm{cm}$ was used in the experiments.

\subsection{Instrumentation and analyses methods}

X-ray powder diffraction (XRD) patterns of am-ZrP were recorded by a Philips PW3710 X-ray powder diffractometer with the setting of: $40 \mathrm{kV}, 40 \mathrm{~mA}, \mathrm{Cu}-\mathrm{K} \alpha$ radiation $(\lambda=1.54056 \AA$ ). Fourier transform infrared (FT-IR) spectra $\left(400-4000 \mathrm{~cm}^{-1}\right)$ were recorded on a Perkin Elmer Spectrum one FT-IR spectrometer fitted with Universal Attenuated Total Reflectance sampling accessory. Thermogravimetry (TG) was performed on a Mettler Toledo TGA850 in $\mathrm{N}_{2}$ flow with a heating rate of $10{ }^{\circ} \mathrm{C} \mathrm{min}{ }^{-1}$. Scanning electron microscope (SEM) images were collected using a Hitachi Hi-Tech S-4800 FESEM. A digital pH meter (Orion model 920A) was used for the $\mathrm{pH}$ measurements. Solid-state ${ }^{31} \mathrm{P}$ magic angle spinning nuclear magnetic resonance $\left({ }^{31} \mathrm{P}\right.$ MAS NMR) spectra were obtained with a Bruker Avance III NMR spectrometer operating at $500 \mathrm{MHz}$ for protons. The spectra were externally referenced to $85 \% \mathrm{H}_{3} \mathrm{PO}_{4}$. A microwave plasma-atomic emission spectrometer (MP-AES) Agilent 4200 was used for analysis of metal ions. The element content of $\mathrm{P} / \mathrm{Zr}$ was measured by MPAES by dissolving weighed am-ZrP powder in a mixture of $65 \% \mathrm{HNO}_{3}$ and $1 \% \mathrm{HF}$ using a CEM MARS 5 microwave digestion system.

\subsection{Synthesis of am-ZrP by precipitation}

$\mathrm{Am}-\mathrm{ZrP}$ was prepared via room-temperature precipitation synthesis method at room temperature according to the method described by Krogh Andersen et al. (1998). First, $30.7 \mathrm{~g}$ of $\mathrm{ZrCl}_{4}$ was carefully dissolved in $430 \mathrm{~mL}$ of $2 \mathrm{M}$ $\mathrm{HCl}$. Then, $400 \mathrm{~mL}$ of $1.25 \mathrm{M} \mathrm{H}_{3} \mathrm{PO}_{4}$ was added to the previous solution. The resulting precipitated solid was allowed to stand over night and was then filtered using a filter paper $(2.5 \mu \mathrm{m}$ (Particle retention)). The white solid was then washed with $1 \mathrm{~L}$ of $2 \mathrm{M} \mathrm{H}_{3} \mathrm{PO}_{4}$ in order to remove the unbound $\mathrm{Cl}^{-}$ions. Subsequently, $1 \mathrm{~L}$ of $1 \mathrm{M} \mathrm{HNO}_{3}$ was poured over the filtrate to purify the product and to ensure full conversion to $\mathrm{H}$-form. Finally, the am-ZrP product was rinsed with deionized water until the $\mathrm{pH}$ of the filtrate reached 3 , and dried in an oven at $60{ }^{\circ} \mathrm{C}$ for $48 \mathrm{~h}$.

\subsection{Preparation of ternary Co-Nd-Dy solution}

The ternary $\mathrm{Co}, \mathrm{Nd}$, and Dy solution was prepared by mixing their corresponding nitrate salts and the solution $\mathrm{pH}$ was adjusted by $1 \mathrm{M} \mathrm{HNO}_{3}$. Solutions containing 0.01 to $10 \mathrm{mM}$ of each metal were prepared at $\mathrm{pH} 3$ for batch ion exchange experiments. A feed solution containing $1 \mathrm{mM}$ of each metal was prepared at $\mathrm{pH} 1.8$ for column studies. 


\subsection{Potentiometric Titration}

The direct titration (from $\mathrm{H}$ to $\mathrm{Na}$ form) of the prepared am-ZrP was conducted in a series of batch experiments where $100 \mathrm{mg}$ of am-ZrP was placed into $19 \mathrm{~mL}$ of deionized water or $1.0 \mathrm{M} \mathrm{NaNO}_{3}$ solution and adding different amounts $(250-1050 \mu \mathrm{L})$ of $1 \mathrm{M} \mathrm{NaOH}$ solution. The samples were equilibrated for three days in a rotary mixer $(60 \mathrm{rpm})$ and their equilibrium $\mathrm{pH}$ values were measured.

\subsection{Effect of $\mathrm{pH}$ studies}

A $100 \mathrm{mg}$ quantity of am-ZrP was placed into a $20 \mathrm{~mL}$ polyethylene vial filled with $20 \mathrm{~mL}$ of $1 \mathrm{mM}$ equimolar Co, Nd and Dy at different pHs (1-6). The vials were equilibrated in a rotary mixer $(60 \mathrm{rpm})$ for three days. After the initial 24 $\mathrm{h}$, the $\mathrm{pH}$ value of each solution was checked and adjusted when necessary with $1 \mathrm{M} \mathrm{NaOH}$. Phase separation was achieved by centrifugation at $4000 \mathrm{rpm}(3000 \mathrm{~g})$ for $15 \mathrm{~min}$ after which the $\mathrm{pH}$ of the supernatants were measured and finally metal concentration determination with MP-AES.

\subsection{Adsorption kinetic studies}

Investigation of sorption kinetics were carried out for different reaction times (from $0.25 \mathrm{~h}$ to $72 \mathrm{~h}$ ). A $100 \mathrm{mg}$ quantity of am-ZrP was placed into a $20 \mathrm{~mL}$ polyethylene vials with $20 \mathrm{~mL}$ of $1 \mathrm{mM}$ equimolar $\mathrm{Nd}$ and Dy solutions at $\mathrm{pH} 3$. The metal concentrations of supernatants were determined with MP-AES.

\subsection{Isotherm studies}

A $100 \mathrm{mg}$ quantity of am-ZrP was equilibrated for 3 days with $20 \mathrm{~mL}$ of ternary Co-Nd-Dy solutions $(0.01-10 \mathrm{mM}$ with an adequate interval) at pH 3 in a rotary mixer $(60 \mathrm{rpm})$. The concentrations of $\mathrm{Co}, \mathrm{Nd}$ and Dy in the supernatants were measured by MP-AES.

\subsection{Batch elution studies}

A $100 \mathrm{mg}$ quantity of am-ZrP was placed into $20 \mathrm{~mL}$ polyethylene vials into which $20 \mathrm{~mL}$ of $10 \mathrm{mM}$ equimolar Co, $\mathrm{Nd}$ and Dy solutions were added, and the mixture was allowed to equilibrate for three days. Then the phase separation was achieved by centrifugation as described above. The solids were washed three times with deionized water and dried at $60{ }^{\circ} \mathrm{C}$ for $24 \mathrm{~h}$. Subsequently, $20 \mathrm{~mL}$ of $0.1,0.3$ and $1 \mathrm{M} \mathrm{HCl}, \mathrm{HNO}_{3}, \mathrm{H}_{3} \mathrm{PO}_{4}$ and $\mathrm{H}_{2} \mathrm{SO}_{4}$ eluents were pipetted into their respective vials and then rotated for three days to achieve equilibrium. The supernatants were collected for measurements. 


\subsection{Column loading/elution experiments}

Column tests were performed in a Bio-Rad glass column with an inner diameter of $10 \mathrm{~mm}$ at room temperature (22-

$\left.23^{\circ} \mathrm{C}\right)$. The columns were filled with am-ZrP material $(1.76 \mathrm{~g})$, which was carefully packed up to a height of around 55 $\mathrm{mm}$ in the columns. A ternary solution, $1 \mathrm{mM}$ equimolar Co-Dy-Nd with a $\mathrm{pH}$ value of 1.8 was prepared as the feed solution. The feeding was carried out to various loading degrees (about 8\%, 62\% and 100\%). The column was subsequently washed with 6 bed volumes (BVs) of a $\mathrm{pH} 1.8$ aqueous $\mathrm{HNO}_{3}$ solution. After this the elution process was started using 0.1-0.5 $\mathrm{M} \mathrm{HNO}_{3}$ as the eluting agent. Samples were collected from the column outlet using a fraction collector for MP-AES measurements. The loading, washing and eluting speed was set at around 2 BV/h throughout the study.

\section{Theory of ion exchange}

Considering a binary ion exchange between ions $B^{z_{B}}$ and $A^{z_{A}}$, can be expressed as:

$$
z_{B} A^{z_{A}}+z_{A} \bar{B}^{z_{B}} \leftrightharpoons z_{B} \bar{A}^{z_{A}}+z_{A} B^{z_{B}}
$$

Where the barred symbols refer to the ions of the solid phase, and $\mathrm{z}_{\mathrm{A}}$ and $\mathrm{z}_{\mathrm{B}}$ are ion charges of $\mathrm{A}$ and $\mathrm{B}$ ions.

The distribution coefficient $\left(\mathrm{K}_{\mathrm{d}}\right)$ describes the distribution of solute ions between the solution and the ion exchanger, e.g. for ion A:

$K_{\mathrm{d}}=\frac{[\bar{A}]}{[A]}$

It can be calculated from solution phase measurements of A by

$$
K_{\mathrm{d}}=\frac{\left[A_{0}\right]-[A]}{[A]} \times \frac{V}{m}
$$

Where $\left[\mathrm{A}_{0}\right]$ is the solution concentration of $\mathrm{A}$ initially and $[\mathrm{A}]$ is the corresponding concentration at equilibrium. $\mathrm{V}$ is the volume of solution and $\mathrm{m}$ is the mass of the exchanger material.

The separation factor (SF) can be described as the comparison of distribution coefficients to one another: 
$S F(A / B)=\frac{K_{d}^{A}}{K_{d}^{B}}$

Here $K_{d}^{A}$ and $K_{d}^{B}$ is the distribution coefficient of ion A and ion B.

When considering the exchange of metal ions $\mathrm{M}^{\mathrm{n}+}$ for hydronium ions $\mathrm{H}^{+}$Eq. 2 for the selectivity coefficient becomes

$k_{\mathrm{M} / \mathrm{H}}=\frac{[\bar{M}] H]^{n}}{[M][\bar{H}]^{n}}$

In cases when metal loading in exchanger is low in the system $([\bar{M}] \ll<[\bar{H}] \approx \mathrm{Q}$ and $[\mathrm{M}] \ll<[\mathrm{H}])$

$\log K_{d}=\log \left(k_{\frac{M}{H}} Q^{n}\right)-n \log [H]=\log \left(k_{\frac{M}{H}} Q^{n}\right)+n p H$

Thus, $\log \mathrm{K}_{\mathrm{d}}$ is linear as a function of $\mathrm{pH}$ with a slope of $+\mathrm{n}$. Here, $\mathrm{Q}$ is the total capacity of the ion

exchanger.

Equivalent fractions or mole fractions are often used as substitute for molarities or molarities. For example, the equivalent fraction of $\mathrm{M}^{\mathrm{n}+}$ in the sorbent can be expressed as:

$\overline{E_{M}}=\frac{z_{M} q_{M}}{Q}$

Where $z_{M}$ is M ion's charge, $q_{M}$ is the equilibrium concentration in the sorbent $(\mathrm{mM} / \mathrm{g})$ and $Q$ is the ion exchange capacity of the ion exchanger (meq/g).

The elution percentage (Elution \%) is calculated from

Elution $\%=\left(1-\frac{q_{e q}}{q_{i}}\right) \times 100=\left(1-\frac{q_{i}-C_{e q}(V / m)}{q_{i}}\right) \times 100$

Where $\mathrm{q}_{\mathrm{i}}$ is the initial amount of $\mathrm{M}$ loaded in the sorbent and $\mathrm{q}_{\mathrm{eq}}$ is the amount of $\mathrm{M}$ in sorbent after eluting. $\mathrm{C}_{\mathrm{eq}}$ is metal concentration in the batch elution solution at equilibrium. The $\mathrm{K}_{\mathrm{d}}$ is determined from

$$
K_{d}=\frac{q_{e q}}{C_{e q}}=\left(\frac{q_{i}-C_{e q}(V / m)}{C_{e q}}\right)
$$


The symbols are the same as those in Eq. 8.

\section{Results and discussion}

\subsection{Characterizations of am-ZrP}

The $\mathrm{P} / \mathrm{Zr}$ ratio of the synthesized am-ZrP was determined to be 2.03 by total digestion, which was very close to the ideal stoichiometry of 2. The XRD powder diffraction pattern of am-ZrP (Fig. 1) demonstrated the amorphous nature of the material exhibiting some broad and low intensity peaks at $10-60^{\circ}$ degrees. The SEM image (Fig. 1b) showed irregular crystal morphology. The IR of the am-ZrP (Fig. 1c) had a band at $987 \mathrm{~cm}^{-1}$ which could be ascribed to the P-O deformation and vibration of the orthophosphate group (Horsley et al., 1974). The weak peak at $1621 \mathrm{~cm}^{-1}$ indicated the bending of $-\mathrm{OH}$ group water molecule (Tarafdar et al., 2006).
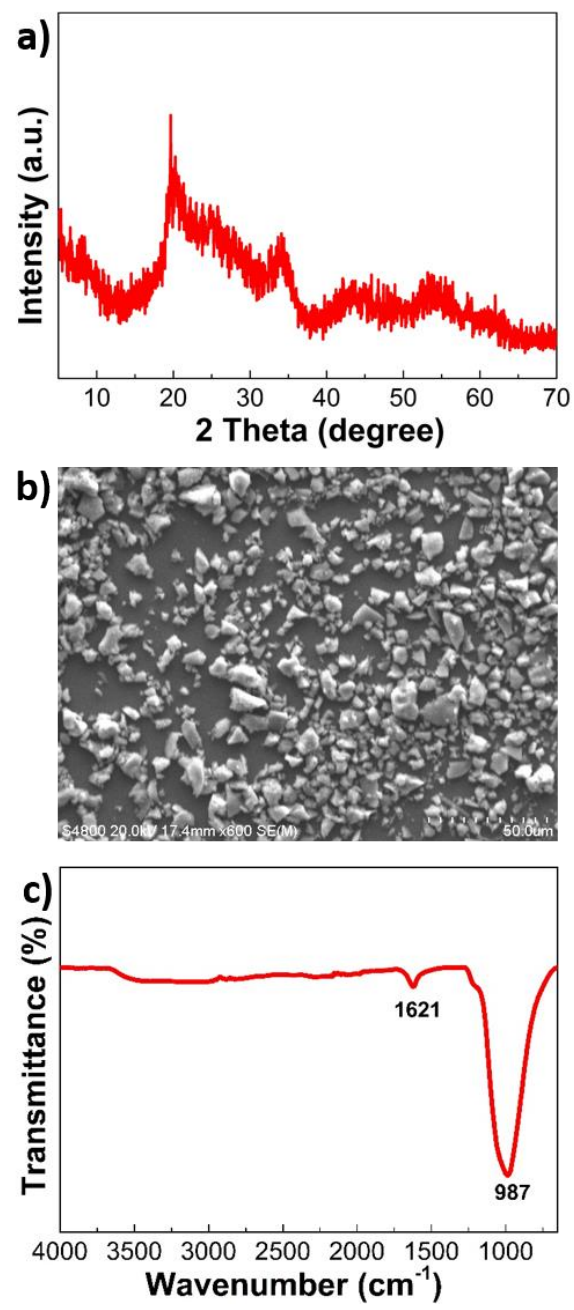

Fig. 1. The X-ray powder diffraction pattern a), SEM image b) and FTIR spectrum c) of the synthesized am-ZrP. 
The ${ }^{31} \mathrm{P}$ MAS NMR spectrum consisting of three peaks (Fig. 2) gave further information on the am-ZrP's composition. The peaks at -13.6 ppm, $-21.7 \mathrm{ppm}$, and -27.5 ppm can be assigned to the $\mathrm{H}_{2} \mathrm{PO}_{4}^{-}$group, the $\mathrm{HPO}_{4}{ }^{2-}$ group and the $\mathrm{PO}_{4}{ }^{3-}$ group, respectively (Jones et al., 1989; Hudson \& Workman, 1991). According to the line deconvolution results, the estimated ratio of $\mathrm{H}_{2} \mathrm{PO}_{4}{ }^{-}: \mathrm{HPO}_{4}{ }^{2-}: \mathrm{PO}_{4}{ }^{3-}$ group was 9.3:100:4.8, based on the intensity of the three resonances (Zhang et al., 2017). In addition, TGA (Fig. 2 b) showed two weight loss regions, $7.07 \%$ from $25^{\circ} \mathrm{C}$ to $184{ }^{\circ} \mathrm{C}$ and $4.98 \%$ from $184^{\circ} \mathrm{C}$ to $800{ }^{\circ} \mathrm{C}$. From this we can assume that first the physically bound water was released, that was followed by the condensation of $\mathrm{H}_{2} \mathrm{PO}_{4}$ groups. All these processes had considerably overlapped and occurred simultaneously, that has also been reported earlier (Bortun et al., 1997). The XRD pattern of am-ZrP calcined in $800^{\circ} \mathrm{C}$ (Fig. 2 c) confirmed that the substance at the last step of the TGA was $\mathrm{ZrP}_{2} \mathrm{O}_{7}$ (Samed et al., 2011), which was in agreement with the $\mathrm{P} / \mathrm{Zr}$ ratio determined as 2.03. Based on the NMR and TG data a chemical formula $\mathrm{Zr}\left(\mathrm{H}_{2} \mathrm{PO}_{4}\right)_{0.17}$ $\left(\mathrm{HPO}_{4}\right)_{1.78}\left(\mathrm{PO}_{4}\right)_{0.09} \bullet 0.96 \mathrm{H}_{2} \mathrm{O}$ can be suggested for this am- $\mathrm{ZrP}$ material. The theoretical ion exchange capacity of the material can then be calculated as $6.97 \mathrm{meq} / \mathrm{g}$.
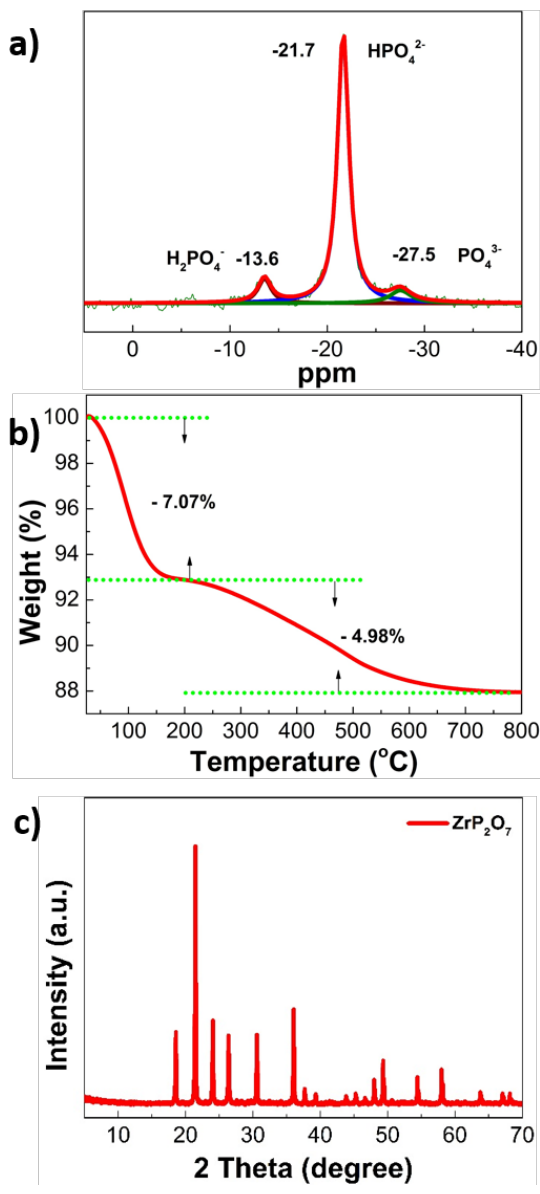

Fig. 2. The ${ }^{31} \mathrm{P}$ MAS NMR spectrum with its corresponding line deconvolution peaks a), the TGA curve b) of synthesized am-ZrP and the XRD pattern $(2 \theta$ angle from 5-70 $)$ of am- $\mathrm{ZrP}$ calcined in $\left.800{ }^{\circ} \mathrm{C} \mathbf{c}\right)$. 


\subsection{Potentiometric titration}

The titration of am-ZrP displayed a steadily increasing titration curve in deionised water (Fig. 3a) with no clear equivalence points. This suggested that the $\mathrm{H}_{2} \mathrm{PO}_{4}{ }^{-}$and $\mathrm{HPO}_{4}{ }^{-}$groups are gradually exchanged with $\mathrm{Na}^{+}$ions. The ion exchange capacity of am-ZrP can be estimated from the plateau of the curve (Helfferich, 1995) and was found to be 9.2 meq/g. This is much higher than the theoretical capacity of $6.97 \mathrm{meq} / \mathrm{g}$, estimated from the chemical formula and may be due to the hydrolysis of material in alkaline solutions (Bortun et al., 1997).

Titration in $\mathrm{NaNO}_{3}$ solution background is expected to sharpen any equivalence points in weakly acidic ion exchangers due to the shift in the equilibrium $\mathrm{R}-\mathrm{OH}+\mathrm{Na}^{+} \leftrightarrow \mathrm{R}-\mathrm{Na}+\mathrm{H}^{+}$. In this case, no clear equivalence points emerged (Fig. 3 ), though the $1^{\text {st }}$ derivative indicted the presence of an inflection point at about $6.5 \mathrm{meq} / \mathrm{g}$, which was relatively close to the theoretical capacity. Interestingly, the ion exchange capacity estimated from the plateau was about $7.10 \mathrm{meq} / \mathrm{g}$, which was very close to the calculated theoretical value. Added salts are known to decrease the hydrolytic destruction of $\mathrm{ZrP}$ materials (Bortun et al., 1997). Here, the situation was further complicated by the observation that prior to the titration when the $\mathrm{ZrP}$ material was placed in the $1 \mathrm{M} \mathrm{NaNO}_{3}$, the $\mathrm{pH}$ of the solution decreased from 6.5 to 2.60 , indicating that a conversion of $2.13 \mathrm{meq} / \mathrm{g}$ to the Na-form had taken place. Adding this conversion value to the titration plateau again increased the total ion exchange capacity to $9.23 \mathrm{meq} / \mathrm{g}$, which was practically identical to the capacity determined by titration in deionised water.
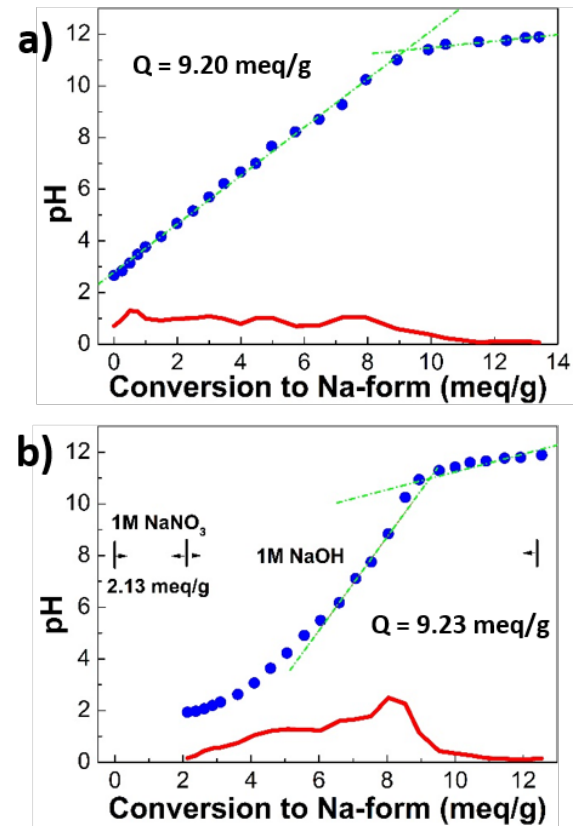

Fig. 3. Titration of pre-prepared am- $\mathrm{ZrP}$ with $1.0 \mathrm{M} \mathrm{NaOH}$ in: a) deionised water, b) in $1 \mathrm{M} \mathrm{NaNO}_{3}$. The solid lines represent the corresponding first derivatives of the titration curves. 
In the crystalline ZrP materials, the equivalence points become more apparent as the degree of crystallinity in the material increases (Xu et al., 2017) and it was possible to determine the values of individual $\mathrm{pK}_{\mathrm{a}}$-values. However, it was not possible to determine these values of am-ZrP material.

\subsection{Kinetic study}

The adsorption kinetics of am-ZrP were studied by determining the characteristic constants of adsorption using a pseudo-first order equation and pseudo-second order equation (Ho \& McKay, 1999; Lee et al., 2007; Zheng et al., 2015).

In the pseudo-first order equation

$$
\log \left(q_{e}-q_{t}\right)=\log q_{e}-\left(\frac{k_{1}}{2.303}\right) t
$$

and in the pseudo-second order equation

$$
\frac{t}{q_{t}}=\frac{1}{k_{2} q_{e}^{2}}+\frac{1}{q_{e}} t
$$

$\mathrm{q}_{\mathrm{e}}\left(\mathrm{mg} \mathrm{g}^{-1}\right)$ and $\mathrm{q}_{\mathrm{t}}\left(\mathrm{mg} \mathrm{g}^{-1}\right)$ are the amounts of Dy and $\mathrm{Nd}$ at equilibrium and at time $\mathrm{t}$, respectivly. $\mathrm{k}_{1}\left(\mathrm{~h}^{-1}\right)$ and $\mathrm{k}_{2}\left(\mathrm{mg} \mathrm{g}^{-1}\right.$ $\mathrm{h}^{-1}$ ) are the rate constants of the pseudo first-order and pseudo-second-order models, respectively.

Intra-particle diffusion equation

$q_{t}=k_{\mathrm{int}} t^{1 / 2}+C$

where $\mathrm{q}_{\mathrm{t}}\left(\mathrm{mg} \mathrm{g}^{-1}\right), k_{\text {int }}\left(\mathrm{mg} \mathrm{g}^{-1} \mathrm{~h}^{1 / 2}\right)$ and $\mathrm{C}\left(\mathrm{mg} \mathrm{g}^{-1}\right)$ are the solute concentration in the sorbent phase at any given time $\mathrm{t}$, the intra-particle diffusion constant and the constant of the proportional to the thickness of boundary layer. A straight line plot of $q_{t}$ and $t^{1 / 2}$ is regarded as the adsorption mechanism that follows the intra-particle diffusion process (Singh et al., 2012).

We observed (Fig. 4a) that a time period of $15 \mathrm{~h}$ was sufficient for the exchange of $\mathrm{Nd}$ and Dy to reach equilibrium. Dy displayed a faster rate in the uptake process and higher uptake than that of $\mathrm{Nd}$ at equilibrium. In terms of the parameters of fitted models (Table 1), the pseudo-second order model for the adsorbtion of Dy and Nd produced much better fits than the corresponding first order equation and intra-particle diffusion model, with correlation coefficients of 0.999 and 
0.998 (Fig. 4b). The results suggested the ion-exchange reaction in our experiment appeared to be the rate-limiting step for the adsorption of $\mathrm{Dy}^{3+}$ and $\mathrm{Nd}^{3+}$ (Ho \& McKay, 1999; Lee et al., 2007; Zheng et al., 2015).
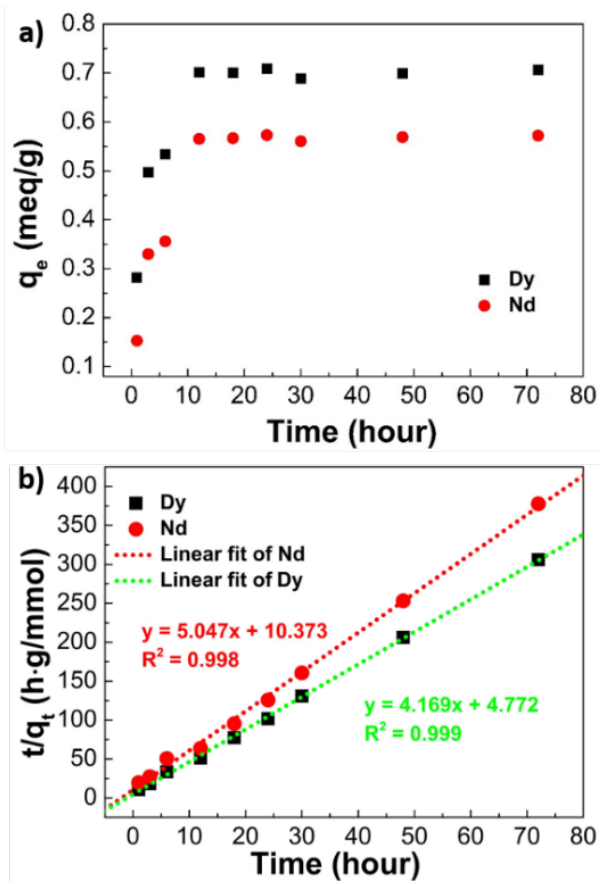

Fig. 4. The effect of contact time on the adsorption kinetics of $1 \mathrm{mM} \mathrm{HNO}_{3}$ solution of $\mathrm{Nd}$ and Dy onto amophous $\mathrm{ZrP}$ $\left(\mathrm{pH}_{\mathrm{eq}} \sim 2.5\right)$ a). Pseudo-second-order adsorption model fitting of Dy and $\mathrm{Nd}$ sorption $\left.\mathbf{b}\right)$.

Table 1 Fitted pseudo-first-order, pseudo-second-order and intra-particle diffusion model parameters for $\mathrm{Nd}$ and Dy adsorption.

\begin{tabular}{|c|c|c|c|c|c|c|c|c|c|c|}
\hline \multirow{2}{*}{$\begin{array}{l}\text { Metal } \\
\text { ion }\end{array}$} & \multirow{2}{*}{$\begin{array}{c}q_{\text {max,exp. }} \\
\left(\mathrm{mmol} \mathrm{g}^{-1}\right)\end{array}$} & \multicolumn{3}{|c|}{ Pseudo-first-order kinetics } & \multicolumn{3}{|c|}{ Pseudo-second-order kinetics } & \multicolumn{3}{|c|}{ Intra-particle diffusion } \\
\hline & & $k_{1}\left(\mathrm{~h}^{-1}\right)$ & $q_{\mathrm{eq}}(\mathrm{mmol}$ & $R^{2}$ & $k_{2}(\mathrm{mg}$ & $q_{\mathrm{eq}}$ & $R^{2}$ & $C$ & $K_{\text {int }}(\mathrm{mmol}$ & \\
\hline & & & $\left.\mathrm{g}^{-1}\right)$ & & $\left.\mathrm{g}^{-1} \mathrm{~h}^{-1}\right)$ & $\left(\mathrm{mmol} \mathrm{g}^{-1}\right)$ & & $\left(\mathrm{mg} \mathrm{g}^{-1}\right)$ & $\left.\mathrm{g}^{-1} \mathrm{~h}^{-1 / 2}\right)$ & $R^{2}$ \\
\hline $\mathrm{Nd}$ & 0.191 & 0.076 & 0.0380 & 0.164 & 2.45 & 0.198 & 0.998 & 12.353 & 2.403 & 0.6257 \\
\hline Dy & 0.236 & 0.064 & 0.0505 & 0.100 & 3.64 & 0.239 & 0.999 & 22.348 & 2.523 & 0.5887 \\
\hline
\end{tabular}

\subsection{Effect of $\mathrm{pH}$ on adsorption}

The uptake of $\mathrm{Nd}$ and Dy reached a maximum plateau at $\mathrm{pH}$ of about 3.0 (Fig. 5 a). The obtained uptake values were $0.610 \mathrm{meq} / \mathrm{g}$ for $\mathrm{Nd}$ and $0.628 \mathrm{meq} / \mathrm{g}$ for Dy. The maximum Co uptake took place at $\mathrm{pH} 3.4$. At this point, the uptakes of Nd, Dy and Co were $0.605 \mathrm{meq} / \mathrm{g}, 0.623 \mathrm{meq} / \mathrm{g}$ and $0.430 \mathrm{meq} / \mathrm{g}$, respectively, which totalled $1.65 \mathrm{meq} / \mathrm{g}$. The uptakes of Co, Dy and $\mathrm{Nd}$ at the lower $\mathrm{pH}$ of 1.87 were $0.03,0.53$ and $0.44 \mathrm{meq} / \mathrm{g}$, respectively. The low Co uptake (ca. 3 equivalent- $\%$ of the total metal uptake) is a promising finding in respect of the Dy and Nd loading and separation 
from Co. Therefore, $\mathrm{pH} 1.87$ was chosen as the suitable $\mathrm{pH}$ value to perform the column study. Inspection of corresponding $\mathrm{K}_{\mathrm{d}}$-values revealed that the adsorption of both Co and $\mathrm{Nd}$ somewhat decreased after reaching their maximum, which can be atributed to the higher Dy affinity (Fig. 5b). The solubility of Co, $\mathrm{Nd}$ and $\mathrm{Dy}$ in the $\mathrm{pH}$ and metal concentration ranges used were confirmed using Minteq Software (Gustafsson, 2006). No indication of precipitates in the test solution was observed.
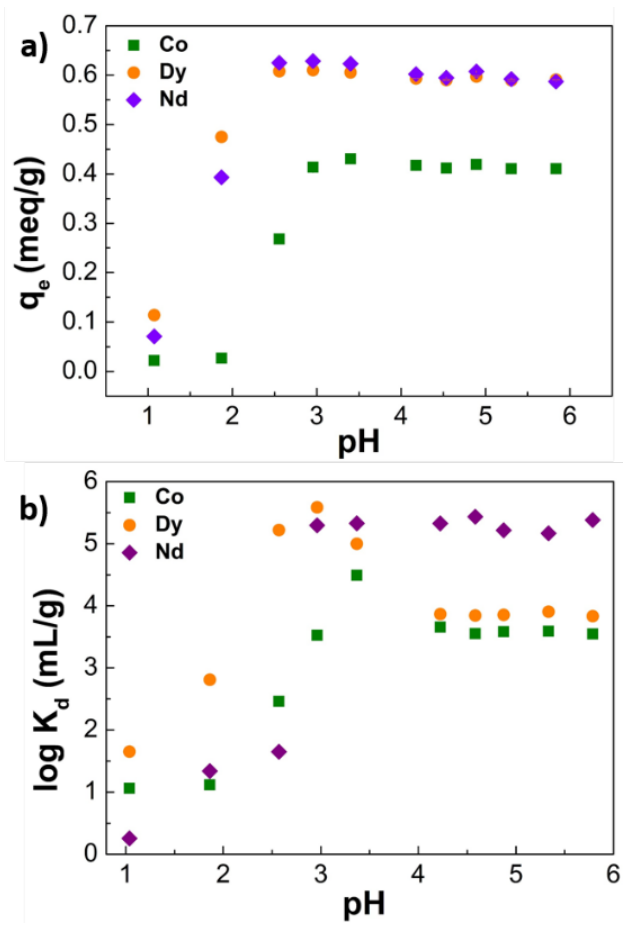

Fig. 5. The effect of $\mathrm{pH}$ on the uptake a) and distribution coeffcient $\mathrm{K}_{\mathrm{d}} \mathbf{b}$ ) of $\mathrm{Co}, \mathrm{Nd}$ and $\mathrm{Dy}$ from $\mathrm{HNO}_{3}$ solution by am-ZrP.

\subsection{Adsorption isotherms and thermodynamics}

The absorbed quantities of $\mathrm{Co}, \mathrm{Nd}$ and $\mathrm{Dy}$ in the adsorption isotherm leveled at about $1 \mathrm{mM}$ concentrations (Fig. 6a).

The highest total uptake amount was $4.13 \mathrm{meq} / \mathrm{g}$ at $7-8 \mathrm{mM}$ equilibrium concentration, which was $59.3 \%$ of the formula-calculated theoretical capacity $6.97 \mathrm{meq} / \mathrm{g}$. The individual metal loading at that point was $0.19 \mathrm{meq} / \mathrm{g}$ of Co, $2.10 \mathrm{meq} / \mathrm{g}$ of Dy and $1.80 \mathrm{meq} / \mathrm{g}$ of Nd. The low proportion of Co(II) uptake can generally be explained as ion exchanges preferentially exchanging cations of higher valence, thus preferring trivalent $\mathrm{Nd}$ and Dy over divalent Co. The calculated separation factor (SF) displayed the order $\mathrm{SF}_{(\mathrm{Dy} / \mathrm{Co})}>\mathrm{SF}_{(\mathrm{Nd} / \mathrm{Co})}>\mathrm{SF}_{(\mathrm{Dy} / \mathrm{Nd})}(\mathrm{Fig} 6 \mathrm{~b})$. It is noteworthy that the highest $\mathrm{SF}(\mathrm{Dy} / \mathrm{Co})(1811), \mathrm{SF}(\mathrm{Nd} / \mathrm{Co})(958)$ and $\mathrm{SF}(\mathrm{Dy} / \mathrm{Nd})(1.9)$ took place at the concentration $\left(\mathrm{C}_{\mathrm{eq}}\right)$ of about 3 $\mathrm{mM}$. 
The binary selectivity coefficients (Fig.6 c) $\mathrm{K}_{\mathrm{Co} / \mathrm{H}}, \mathrm{K}_{\mathrm{Dy} / \mathrm{H}}$ and $\mathrm{K}_{\mathrm{Nd} / \mathrm{H}}$ had similar increasing values from 0.0001 to 0.015 in equivalent fractions $(\overline{\mathrm{E}})$. However, $\mathrm{K}_{\mathrm{Co} / \mathrm{H}}$ exceeded $\mathrm{K}_{\mathrm{Dy} / \mathrm{H}}$ and $\mathrm{K}_{\mathrm{Nd} / \mathrm{H}}$ and had a maximum value when the total metal loading was 0.015 in equivalent fractions $(\overline{\mathrm{E}})$. At high loadings, $\mathrm{K}_{\mathrm{Co} / \mathrm{H}}$ collapsed and $\mathrm{K}_{\mathrm{Dy} / \mathrm{H}}$ and $\mathrm{K}_{\mathrm{Nd} / \mathrm{H}}$ further increased and reached maximum at about $0.05-0.15 \overline{\mathrm{E}}$. These results explain the findings of the column loading experiments (see later) which show that Co is washed out of the $\mathrm{Zr}-\mathrm{P}$ column at higher $\mathrm{Nd}$ and Dy loadings.
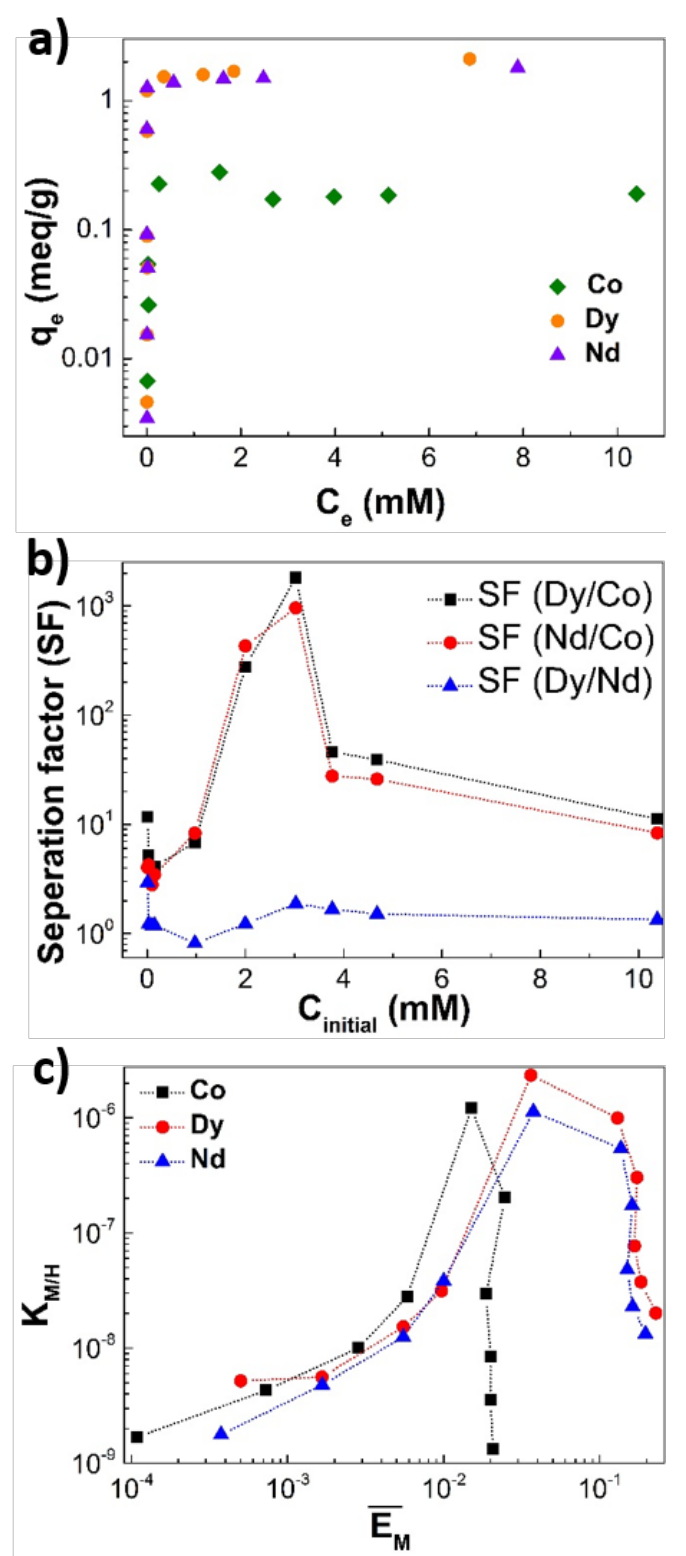

Fig. 6. The isothermal adsorption of $\mathrm{Co}, \mathrm{Nd}$ and $\mathrm{Dy}$ from $\mathrm{HNO}_{3}$ solution range of 0.01 to $10 \mathrm{mM}$ a), the separation factor (SF) of Dy/Co, Nd/Co and Dy/Nd b), The binary selectivity coefficient $\mathrm{K}_{\mathrm{M} / \mathrm{H}}(\mathrm{M}=\mathrm{Co}$, Dy and Nd ) by am-ZrP $\left(\mathrm{pH}_{\mathrm{eq}} \sim 2.5\right), \overline{\mathrm{E}}_{\mathrm{M}}(\mathrm{M}=\mathrm{Co}$, Dy and $\mathrm{Nd})$ is equivalent fractions $\left.\mathbf{c}\right)$. 


\subsection{Batch elution tests}

Sulfuric acid was the most efficent mineral acid for elution, as it was found to elute $85 \%$ of $\mathrm{Nd}$ and $83 \%$ of Dy at $1.0 \mathrm{M}$ concentration in a single batch contact (Table 2). By comparison the other studied acids eluted $73-78 \%$ of the REEs at this concentration. A similar pattern emerged at $0.1 \mathrm{M}$ concentration although there was more difference in the elution efficiency, which decreased in the following order:

$\mathrm{H}_{2} \mathrm{SO}_{4}>\mathrm{HNO}_{3}>\mathrm{HCl}>\mathrm{H}_{3} \mathrm{PO}_{4}$. Moreover, $\mathrm{HCl}$ and $\mathrm{H}_{3} \mathrm{PO}_{4}$ provided a low degree of eluting $(<30 \%)$ at this concentration. Based on the $\mathrm{K}_{\mathrm{d}}$-values, the predicted elution volumes with $\mathrm{H}_{3} \mathrm{PO}_{4}$ of $2102 \mathrm{~mL} / \mathrm{g}$ for $\mathrm{Nd}$, and $\mathrm{HCl}$ of $860 \mathrm{~mL} / \mathrm{g}$ for Dy at $0.1 \mathrm{M}$ concentration would be impractical. The separation factors $(\mathrm{SF}(\mathrm{Dy} / \mathrm{Nd}))$, obtained by the ratio of $\mathrm{K}_{\mathrm{d}}$ values (Eq 5, Table 2) decreased in the order of $\mathrm{SF}(\mathrm{Dy} / \mathrm{Nd}) 1.76(\mathrm{HCl})>1.16$ $\left(\mathrm{HNO}_{3}\right)>0.85\left(\mathrm{H}_{2} \mathrm{SO}_{4}\right)>0.69\left(\mathrm{H}_{3} \mathrm{PO}_{4}\right)$.

Table 2. Batch elution data calculated by elution \% (Eq.8) and $\mathrm{K}_{\mathrm{d}}$ (Eq.9) of am-ZrP in different mineral acids

\begin{tabular}{lllllll}
\hline Eluting agent & \multicolumn{2}{l}{ Elution (\%) } & \multicolumn{2}{c}{$\mathrm{K}_{\mathrm{d}}(\mathrm{mL} / \mathrm{g})$} & \multirow{2}{*}{$\mathrm{SF}(\mathrm{Dy} / \mathrm{Nd})$} \\
\cline { 3 - 5 } & & $\mathrm{Dy}$ & $\mathrm{Nd}$ & $\mathrm{Dy}$ & $\mathrm{Nd}$ & \\
\hline $\mathrm{H}_{3} \mathrm{PO}_{4}$ & $0.1 \mathrm{M}$ & 12.0 & 8.6 & 1458 & 2102 & 0.7 \\
& $1 \mathrm{M}$ & 73.2 & 75.2 & 73 & 66 & 1.2 \\
$\mathrm{H}_{2} \mathrm{SO}_{4}$ & $0.1 \mathrm{M}$ & 77.7 & 74.8 & 57 & 67 & 0.9 \\
& $1 \mathrm{M}$ & 85.1 & 82.6 & 35 & 42 & 0.8 \\
$\mathrm{HCl}$ & $0.1 \mathrm{M}$ & 18.9 & 29.0 & 860 & 490 & 1.8 \\
& $1 \mathrm{M}$ & 78.2 & 72.7 & 56 & 75 & 0.8 \\
$\mathrm{HNO}_{3}$ & $0.1 \mathrm{M}$ & 56.6 & 60.2 & 153 & 132 & 1.2 \\
& $1 \mathrm{M}$ & 75.0 & 70.9 & 67 & 82 & 0.8 \\
\hline
\end{tabular}

\subsection{Column separation}

The feed of $435 \mathrm{BV}$ of solution resulted in full loading (totally $2.43 \mathrm{meq} / \mathrm{g}$, Table 3 ) and complete breakthrough of Co, Nd and Dy in the column outlet (Fig. 7 a). Individual metal breakthrough started at 20, 125 and $135 \mathrm{BV}$ for $\mathrm{Co}, \mathrm{Nd}$ and Dy respectively. The Co concentration exceeded the initial feed concentration by about $20 \%$ after full breakthrough due to the desorption caused by uptake of $\mathrm{Nd}$ and $\mathrm{Dy}$. Furthermore, a desorption of Nd caused by uptake of Dy took place after full Nd breakthrough. Similar 
pattern was observed in the static isotherm study (Fig. 6a). Feed of $\sim 137$ and $\sim 12 \mathrm{BV}$ of solution resulted in $62 \%$ and $7.8 \%$ total loadings, respectively (Figs $7 \mathrm{c}$ and $7 \mathrm{~d}$ ).

The elution experiments indicated that the elution peak of $\mathrm{Nd}$ appeared before that of Dy (Fig. $7 \mathrm{~b}, \mathrm{~d}, \mathrm{f}$ ).

Practically no Co was measured in the experiment of $62 \%$ and $100 \%$ loadings, which infers that it was removed during the loading and washing stage. Two more elution peaks appeared for Dy subsequent to the appearance of the first one. It is plausible that this phenomenon was caused by the desorption of Dy from the different phosphate groups of am- $\mathrm{ZrP}$ but the question arises as to why this was not observed for $\mathrm{Nd}$.

The metals in the eluting curves Fig. $7 \mathrm{~b}$ and $\mathrm{d}$ did not show separate elution bands because at $100 \%$ and $62 \%$ (calculated from the data of Table 3) loading there was not enough space for the separate elution bands to form in the effluent. At $7.8 \%$ loading three separate elution bands appeared where Co was first to be eluted followed by Nd and Dy. There was only a slight overlap between Nd and Dy at 25-32 BV.
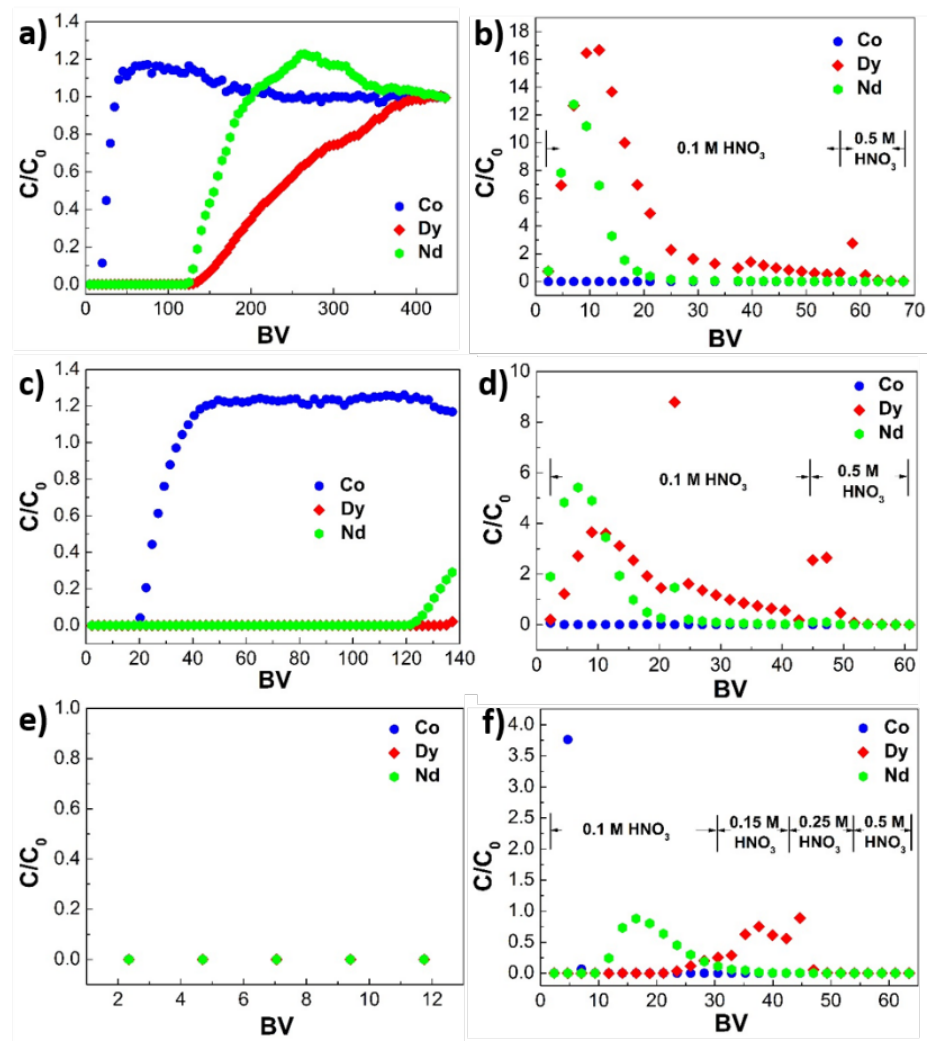

Fig. 7. Loading curves of $\mathrm{Co}, \mathrm{Nd}$ and $\mathrm{Dy}$ at an initial concentration of $1 \mathrm{mM}(\mathrm{pH} \sim 1.8)$ each with different loading volumes of $\sim 435 \mathrm{BV}$ (100\% loading) a), 137 BV (62\% loading) c), and 12BV (7.8\% loading) e), respectively.

Corresponding eluting curves b), d) and f) using $\mathrm{HNO}_{3}$ as eluting agent in different concentration. 
Table 3. The mass balance of different eluting processes using $\mathrm{HNO}_{3}$

\begin{tabular}{lcccccccccc}
\hline Loading degree & \multicolumn{3}{c}{$\mathbf{1 0 0 \%}$} & \multicolumn{3}{c}{$\mathbf{6 2 \%}$} & \multicolumn{5}{c}{$\mathbf{7 . 8 \%}$} \\
& & & & & & & & \\
& Co & Dy & Nd & Co & Dy & Nd & Co & Dy & Nd \\
\hline Loading (meq/g) & 0.017 & 1.58 & 0.83 & 0.17 & 0.77 & 0.76 & 0.05 & 0.08 & 0.08 \\
Washing (meq/g) & 0.017 & 0.059 & 0.062 & 0.017 & 0.00 & 0.023 & 0.00 & 0.00 & 0.00 \\
Eluting (meq/g) & 0.00 & 1.54 & 0.65 & 0.00 & 0.58 & 0.36 & 0.04 & 0.066 & 0.069 \\
Recovery (\%) & 100 & 98.9 & 84.4 & 100 & 75.8 & 48.8 & 75 & 81.8 & 84.6 \\
\hline
\end{tabular}

Separation factor ( $\mathrm{SF}(\mathrm{Dy} / \mathrm{Nd}))$ of Dy/Nd in the column eluting experiments (Fig. $7 \mathrm{~b}, \mathrm{~d}, \mathrm{f})$ was calculated as a ratio of corresponding to peak positions. The $\mathrm{SF}(\mathrm{Dy} / \mathrm{Nd})$ were $2.2,1.3$ and 1.7 corresponding to the loading degree $7.8 \%, 62 \%$ and $100 \%$, respectively (Fig. 8). The $7.8 \%$ loaded with the highest SF of 2.2 demonstrates that there was more space for the elution bands to be separated in the column. It is worth noting that $\mathrm{SF}(\mathrm{Dy} / \mathrm{Nd})$ of $62 \%$ loaded was less than that of $100 \%$ loaded (Figure 8), the reason could be the different ratio of the loaded Dy and Nd elements. The $100 \%$ loaded Dy: Nd ratio 2.1 was higher than that of $62 \%$ loaded 1.0 since $\mathrm{Nd}$ was displaced by Dy in the $100 \%$ loading process. Nevertheless, at $100 \%$ and $62 \%$ loadings the elution peaks of $\mathrm{Nd}$ and Dy overlapped too much for efficient separation to occur. The overlap would be probably be too severe even for industrial moving bed systems that can handle partially separated peaks. Only at the $7.8 \%$ loading was there sufficient separation of the $\mathrm{Nd}$ and Dy peaks, even for a single column operation. The purity of the Nd elution peak with respect of Dy was $100 \%$ and that of Dy elution peak with respect to $\mathrm{Nd}$ was $99 \%$. Obviously, the separation system can be optimized to increase the degree of metal loading and column utilization and to increase the elution times. 


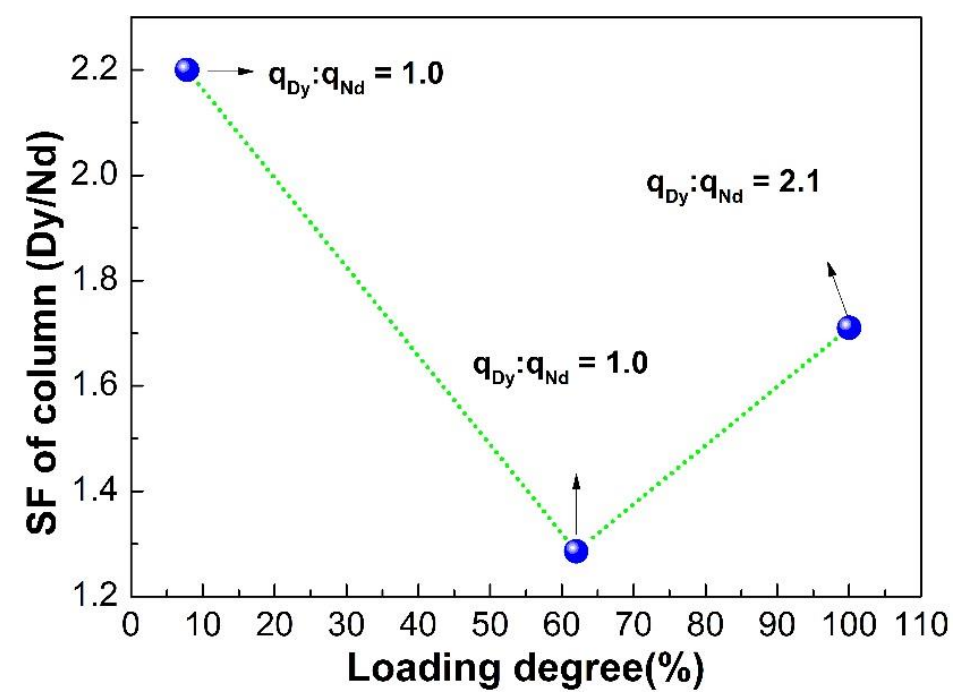

Fig. 8 Column separation factor (SF) as a function of loading degree and the ratio of Dy and Nd loading degree.

\section{Conclusions}

An am-ZrP ion exchanger was synthesized using a precipitation synthesis method at room temperature. The am-ZrP contained three different phosphate groups: $\mathrm{H}_{2} \mathrm{PO}_{4}^{-}, \mathrm{HPO}_{4}{ }^{2-}$ and $\mathrm{PO}_{4}{ }^{3-}$ with the ratio of 9.3:100:4.8, based on ${ }^{31} \mathrm{P}$ NMR determination. The theoretical ion exchange capacity that was calculated from the experimentally determined formula $\mathrm{Zr}\left(\mathrm{H}_{2} \mathrm{PO}_{4}\right)_{0.17}\left(\mathrm{HPO}_{4}\right)_{1.78}\left(\mathrm{PO}_{4}\right)_{0.09} \bullet 0.96 \mathrm{H}_{2} \mathrm{O}$, was $6.97 \mathrm{meq} / \mathrm{g}$. The uptakes of Dy and Nd followed the pseudo second-order model, which indicated that the rate-limiting step was the chemical adsorption process. Compared to the total metal loading, the uptake of Co was small, about $4.6 \%$ at metal equilibrium concentration of 7-8 mM, which suggested a good separation between Dy and $\mathrm{Nd}$, both of which have a valence of three and metals such as Co with a valence of two. The elution efficiency of the respective eluting agent at $0.1 \mathrm{M}$ concentration followed in the order $\mathrm{H}_{2} \mathrm{SO}_{4}>\mathrm{HNO}_{3}>\mathrm{HCl}>\mathrm{H}_{3} \mathrm{PO}_{4}$. The column loading and eluting experiments showed that the high degrees of metal loading (100\% and 62\%) resulted in poor separation of the $\mathrm{Nd}$ and Dy elution peaks. However, at metal loading of $7.8 \%$, three clear bands appeared using only dilute $\mathrm{HNO}_{3}$ as the eluting agent. These promising results indicate it should be straightforward to optimize further the degree of metal loading and eluant concentration for the most efficient separation of $\mathrm{Nd}$ and $\mathrm{Dy}$. 


\section{Acknowledgments}

The research leading to these results received funding from the European Community's Seventh Framework Programme ([FP7/2007-2013]) under grant agreement no. 607411 (MC-ITN EREAN: European Rare Earth Magnet Recycling Network, http://www.erean.eu). This publication reflects only the authors' views, exempting the Community from any liability. 


\section{References}

Bestaoui, N., Spurr, N.A., Clearfield, A. 2006. Intercalation of polyether amines into $\alpha$-zirconium phosphate. J. Mater. Chem., 16(8), 759-764.

Binnemans, K., Jones, P.T., Blanpain, B., Van Gerven, T., Yang, Y., Walton, A., Buchert, M. 2013. Recycling of rare earths: a critical review. J. Clean. Prod., 51, 1-22.

Bortun, A.I., Bortun, L.N., Clearfield, A., Khainakov, S.A., Strelko, V.V., Khryashevskii, V.N., Kvashenko, A.P., Voitko, I.I. 1997. Synthesis and characterization of ion exchange properties of spherically granulated titanium phosphate. Solvent Extra. Ion Exch., 15(3), 515-532.

Brown, C.G. and L.G. Sherrington, Solvent extraction used in industrial separation of rare earths. 1979. J. Chem. Tech. Biotech, 29(4), 193-209.

Clearfield, A. 1984. Inorganic ion exchangers with layered structures. Annu. Rev. Mater. Sci., 14(1), 205-229.

Cook, R.L., Sammells, A.F. 1991. On the systematic selection of perovskite solid electrolytes for intermediate temperature fuel cells. Solid State Ion., 45(3-4), 311-321.

Dupont, D., Binnemans, K. 2015. Recycling of rare earths from NdFeB magnets using a combined

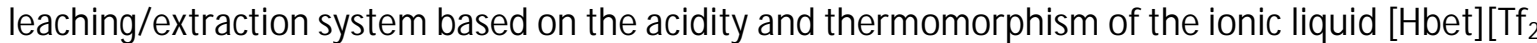
N]. Green Chem., 17(4), 2150-2163.

Dyer, A., Shaheen, T., Zamin, M. 1997. Ion exchange of strontium and caesium into amorphous zirconium phosphates. J. Mater. Chem., 7(9), 1895-1899.

El-M oneim, A., Gebert, A., Uhlemann, M., Gutfleisch, O., Schultz, L. 2002. The influence of Co and Ga additions on the corrosion behavior of nanocrystalline NdFeB magnets. Corrosion Sci., 44(8), 1857 1874.

Emig, G., Hofmann, H. 1983. Action of zirconium phosphate as a catalyst for the oxydehydrogenation of ethylbenzene to styrene. J. Catal., 84(1), 15-26.

Gustafsson, J.P. 2006. Visual minteq. Capturado em de, 26

Helfferich, F. 1995. Ion Exchange. Dover Publications, New York. 81-88.

Ho, Y.-S., M cKay, G. 1999. Pseudo-second order model for sorption processes. Process Biochem., 34(5), 451465.

Horsley, S., Nowell, D., Stewart, D. 1974. The infrared and Raman spectra of $\alpha$-zirconium phosphate. Spectrochim. Acta. A: Mol. Spectrosc., 30(2), 535-541.

Hudson, M.J., Workman, A.D. 1991. High-resolution solid-state ${ }^{31} \mathrm{P}$ and ${ }^{119} \mathrm{Sn}$ magic-angle spinning nuclear magnetic resonance studies of amorphous and microcrystalline layered metal (IV) hydrogenphosphates. J. Mater. Chem., 1(3), 375-379.

Inamuddin, L.M., Luqman, M. 2012. Ion exchange technology I: theory and materials. Springer. 10, 978-94.

Jones, D.J., Penfold, J., Tomkinson, J., Rozière, J. 1989. Incoherent inelastic neutron scattering studies of proton-conducting materials: $\mathrm{Sn}\left(\mathrm{HPO}_{4}\right)_{2} \cdot \mathrm{H}_{2} \mathrm{O}$ and $\mathrm{HM}\left(\mathrm{SO}_{4}\right)_{2} \cdot \mathrm{H}_{2} \mathrm{O}, \mathrm{M}=\mathrm{Fe}$, In: Part II. The vibrational spectrum of $\mathrm{H}_{3} \mathrm{O}+$. J. Mol. Struct., 197, 113-121.

Krogh Andersen, A.M., Norby, P., Hanson, J.C., Vogt, T. 1998. Preparation and characterization of a new 3dimensional zirconium hydrogen phosphate, $\mathrm{\tau}-\mathrm{Zr}\left(\mathrm{HPO}_{4}\right)_{2}$. Determination of the complete crystal structure combining synchrotron X-ray single-crystal diffraction and neutron powder diffraction. Inorg. chem., 37(5), 876-881.

Kullberg, L., Clearfield, A. 1981. Mechanism of ion exchange in zirconium phosphates. 31. Thermodynamics of alkali metal ion exchange on amorphous zirconium phosphate. J. Phys. Chem., 85(11), 15781584.

Lee, I.-H., Kuan, Y.-C., Chern, J.-M . 2007. Equilibrium and kinetics of heavy metal ion exchange. J. Chin. Inst. Chem. Eng., 38(1), 71-84.

Lehto, J., Harjula, R. 1999. Selective separation of radionuclides from nuclear waste solutions with inorganic ion exchangers. Radiochim. Acta, 86(1-2), 65-70.

M orais, C.A.d. and V. Ciminelli, Process development for the recovery of high-grade lanthanum by solvent extraction. 2004. Hydrometallurgy, 73(3), 237-244. 
Nakamura, T., S. Nishihama, and K. Yoshizuka, Separation and recovery process for rare earth metals from fluorescence material wastes using solvent extraction. 2007. Solvent Extr. Res. Dev. Jpn, 14, 105113.

Rademaker, J.H., Kleijn, R., Yang, Y. 2013. Recycling as a strategy against rare earth element criticality: A systemic evaluation of the potential yield of NdFeB magnet recycling. Environ. Sci. Technol., 47(18), 10129-10136.

Rao, K.N., Sridhar, A., Lee, A.F., Tavener, S.J., Young, N.A., Wilson, K. 2006. Zirconium phosphate supported tungsten oxide solid acid catalysts for the esterification of palmitic acid. Green Chem., 8(9), 790797.

Samed, A.J., Zhang, D., Hinokuma, S., Machida, M. 2011. Synthesis of $\mathrm{ZrP}_{2} \mathrm{O}_{7}$ by hydrothermal reaction and post-calcination. J. Ceram. Soc. Jpn. , 119(1385), 81-84.

Sheridan, R., Williams, A., Harris, I., Walton, A. 2014. Improved HDDR processing route for production of anisotropic powder from sintered NdFeB type magnets. J. Radioanal. Nucl. Chem., 350, 114-118.

Singh, S.K., Townsend, T.G., M azyck, D., Boyer, T.H. 2012. Equilibrium and intra-particle diffusion of stabilized landfill leachate onto micro-and meso-porous activated carbon. Water Res., 46(2), 491499.

Sydorchuk, V., Janusz, W., Khalameida, S., Skwarek, E., Skubiszewska-Zięba, J., Leboda, R., Zazhigalov, V. 2011. Synthesis, structure and some properties of zirconium phosphate/oxide support compositions. J. Therm. Anal. Calorim., 108(3), 1009-1016.

Tarafdar, A., Panda, A., Pradhan, N., Pramanik, P. 2006. Synthesis of spherical mesostructured zirconium phosphate with acidic properties. Micro. M eso. Mater., 95(1), 360-365.

Trublet, M ., Maslova, V. M., Rusanova, D., Antzutkin N. O. 2017. Sorption performances of $\mathrm{TiO}(\mathrm{OH})\left(\mathrm{H}_{2} \mathrm{PO}_{4}\right) \cdot \mathrm{H}_{2} \mathrm{O}$ in synthetic and mine waters. RSC Adv., 7(4), 1989-2001.

Walton, A., Yi, H., Rowson, N., Speight, J., Mann, V., Sheridan, R., Bradshaw, A., Harris, I., Williams, A. 2015. The use of hydrogen to separate and recycle neodymium-iron-boron-type magnets from electronic waste. J. Clean. Prod., 104, 236-241.

Xie, F., Zhang, T.A., Dreisinger, D., Doyle, F. 2014. A critical review on solvent extraction of rare earths from aqueous solutions. M iner. Eng., 56, 10-28.

Xu, J., Wiikinkoski, E., Koivula, R., Zhang, W., Ebin, B., Harjula, R. 2017. HF-Free Synthesis of $\alpha$-Zirconium Phosphate and Its Use as Ion Exchanger for Separation of Nd (III) and Dy (III) from a Ternary Co-NdDy System. J. Sustain. M etall., 3(3), 646-658.

Yang, P. 2011. The chemistry of nanostructured materials. World Scientific.

Yang, Y., Walton, A., Sheridan, R., Güth, K., Gauß, R., Gutfleisch, O., Buchert, M., Steenari, B.-M ., Van Gerven, T., Jones, P.T. 2008. REE Recovery from End-of-Life NdFeB Permanent Magnet Scrap: A Critical Review. J. Sustain. Metall., 3(1), 122-149.

Zhang, Q., Pan, B., Pan, B., Zhang, W., Jia, K., Zhang, Q. 2008. Selective sorption of lead, cadmium and zinc ions by a polymeric cation exchanger containing nano- $\mathrm{Zr}\left(\mathrm{HPO}_{3} \mathrm{~S}\right)_{2}$. Environ. Sci. Technol., 42(11), 4140-4145.

Zhang, W., Koivula, R., Wiikinkoski, E., Xu, J., Hietala, S., Lehto, J., Harjula, R. 2017. Efficient and Selective Recovery of Trace Scandium by Inorganic Titanium Phosphate Ion-Exchangers from Leachates of Waste Bauxite Residue. ACS Sustain. Chem. Eng. 5(4), 3103-3114.

Zheng, X., Wang, C., Dai, J., Shi, W., Yan, Y. 2015. Design of mesoporous silica hybrid materials as sorbents for the selective recovery of rare earth metals. J. Mater. Chem. A, 3(19), 10327-10335. 